\title{
Total Chemical Synthesis of a Non-Fibrillating Human Glycoinsulin
}

Mohammed Akhter Hossain*1,2,3, Ryo Okamoto ${ }^{\# 4}$, John A. Karas ${ }^{5}$, Praveen Praveen ${ }^{1}$, Mengjie Liu ${ }^{1}$, Briony E. Forbes ${ }^{6}$, John D. Wade ${ }^{* 1,2,3}$ and Yasuhiro Kajihara ${ }^{4}$

${ }^{1}$ The Florey Institute of Neuroscience and Mental Health, ${ }^{2}$ The Florey Department of Neuroscience and Mental Health, ${ }^{3}$ School of Chemistry, and ${ }^{5}$ Department of Pharmacology and Therapeutics, The University of Melbourne, Victoria 3010, Australia, ${ }^{4}$ Graduate School of Science, Osaka University, Toyonaka, Osaka, 560-0043 Japan, ${ }^{6}$ Discipline of Medical Biochemistry, College of Medicine and Public Health, Flinders University, South Australia 5042, Australia. 


\section{Abbreviation used}

Fmoc, 9-Fluorenylmethoxycarbonyl

HCTU, 2-(1H-6-chlorobenzotriazol-1-yl)-1,1,3,3- tetramethylaminium hexafluorophosphate;

SPPS, solid-phase peptide synthesis;

Acm, acetamidomethyl;

tBu, tert-butyl;

TFA, trifluoroacetic acid;

TIPS, triisopropylsilane;

TFMSA, trifluoromethanesulfonic acid;

DMF, dimethylformamide;

DIEA, diisopropylethylamine;

DODT, 3,6-dioxa-1,8-octanedithiol;

DPDS, 2,2'-dipyridyl disulfide

RP-HPLC, reversed phase high performance liquid chromatography

MALDI TOF MS, matrix-assisted laser desorption ionization time-of-flight mass spectrometry 


\section{Materials}

Fmoc-protected L- $\alpha$-amino acids and HCTU were purchased from GL Biochem (Shanghai, China).

TentaGel R PHB-Thr (t-Bu) Fmoc (for the synthesis of B-chain) was purchased from Rapp Polymere (Tübingen, Germany) and Rink Amide MBHA LL resin (for the synthesis of A-chain) was purchased from NovaBiochem (subsidiary of Merck, Melbourne, Australia). TFA was obtained from Auspep (Melbourne, Australia). Acetonitrile, dichloromethane, diethyl ether, DMF, and methanol were from Merck (Melbourne, Australia). 2-pyridyl disulfide (DPDS) was purchased from Fluka (Buchs, Switzerland). Human serum (Sigma Lot No SLBX6020) and all other reagents were purchased from Sigma-Aldrich (Sydney, Australia).

\section{Peptide synthesis}

The two peptide chains (A and B) were assembled on preloaded (B chain) or Rink amide (A chain) resins using Fmoc solid phase synthesis on a microwave-assisted liberty peptide synthesizer (CEM Liberty, Mathew, USA). The side chain-protecting groups of Fmoc-amino acids were TFA-labile, except for tBuprotected and Acm-protected cysteine (Cys) in the A-chain (A7 and A20 respectively) and Cys (Acm) in the B-chain (B19). The peptides were synthesized on a 0.1 scale using instrument default protocols with a 4-fold molar excess of Fmoc-protected amino acids $(0.4 \mathrm{mmol})$ that were activated by using 3.8 -fold excess of HCTU in the presence of excess of DIEA. N $\alpha$-Fmoc protecting groups were removed with piperidine/DMF (20\% v/v). The coupling and deprotection steps on the synthesiser were carried out at 75 ${ }^{\circ} \mathrm{C}$ using $25 \mathrm{~W}$ microwave power for $5 \mathrm{~min}$ and $60 \mathrm{~W}$ microwave power for 5 or $3 \mathrm{~min}$, respectively.

\section{Peptide purification by RP-HPLC}

Analytical RP-HPLC analysis of the purified compounds was performed with two Waters RP-HPLC systems: Analytical HPLC Waters ${ }^{\mathrm{TM}} 600$ coupled with a Waters ${ }^{\mathrm{TM}} 2487$ detector and semi-preparative

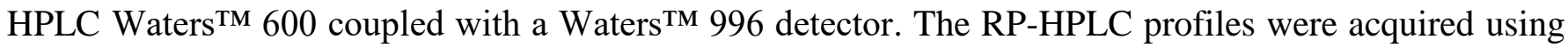

a Phenomenex Gemini C18 analytical column $(4.6 \times 250 \mathrm{~mm}$, pore size $300 \AA$, particle size $5 \mu \mathrm{m})$ at a constant flow rate of $1.5 \mathrm{~mL} / \mathrm{min}$, in a gradient mode with buffer $\mathrm{A}, 0.1 \%$ aq. TFA, and buffer $\mathrm{B}, 0.1 \%$ TFA in acetonitrile, monitoring at a wavelength of $214 \mathrm{~nm}$, which is characteristic for the amide bond. 
All RP-HPLC purifications were performed using a Phenomenex C18 preparative column $(22 \times 250 \mathrm{~mm})$ in a gradient mode with eluent $\mathrm{A}, 0.1 \%$ aq. TFA, and eluent $\mathrm{B}, 0.1 \%$ TFA in acetonitrile.

\section{Peptide characterization by MALDI}

MALDI TOF MS was carried out on a Bruker Ultraflex II instrument (Bruker Daltonics, Bremen, Germany) and used to characterize the peptides at each intermediate step using sinapinic acid (3,5dimethoxy-4 hydroxycinnamic acid) as matrix. The matrix was made up in $75 \%$ acetonitrile containing $0.1 \%$ TFA.

\section{Synthesis of insulin analogue, non-glycoinsulin}

\section{(Figures S1, S2 and S3)}

\section{1}

\section{(1) Fmoc SPPS of A-chain}

The sequence of the A-chain of human insulin (21 residues) is shown in Figure S1. The A-chain (I) was synthesized using the solid phase peptide synthesis (SPPS) method. Fmoc-Asp-OtBu was coupled on to the Rink amide resin (loading $0.36 \mathrm{mmole} / \mathrm{g}$ ) via the side-chain on a $0.1 \mathrm{mmol}$ scale. Cys(tBu) and Cys(Acm) were incorporated at position A7 and A20 respectively.

\section{(2) Fmoc-SPPS of B-chain}

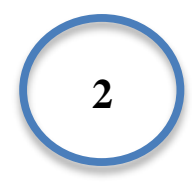

There is an extra amino acid, $\mathrm{Cys}(t \mathrm{Bu})$, incorporated at the $N$-terminus of the $\mathrm{B}$-chain. The sequence of the modified B-chain of insulin (31 residues) is shown in Figure S1. The B-chain (II) of modified human insulin was assembled via microwave-assisted SPPS on a 0.1 mmol scale using preloaded FmocThr(tBu)-TentaGel resin (loading $0.18 \mathrm{mmol} / \mathrm{g}$ ) and Cys(Acm) incorporated at position B19.

Cleavage: The peptides were then detached from the solid support by treating with a cleavage cocktail containing TFA/anisole/DODT/TIPS (94/2.5/1.5/1\%) for $2 \mathrm{~h}$ at RT. The resin was filtered and 
washed with TFA. The filtrate was concentrated by evaporation under a stream of $\mathrm{N}_{2}$ and then precipitated with ice-cold diethyl ether to obtain the peptides as powders. The precipitate was centrifuged at $4000 \mathrm{rpm}$ for $5 \mathrm{~min}$ and washed with ice cold diethyl ether five times. The peptides [Cys6,11(SH), Cys7(tBu), Cys20(Acm)] A-chain (I) and [Cys0(tBu), Cys7(SH), Cys19(Acm)] B-chain (II)] were then freeze dried. The peptide purity was confirmed by analytical RP-HPLC and MALDI TOF MS (A-chain reduced form I $\mathrm{m} / \mathrm{z}$ 2509.616; calcd. 2512.701; B-chain II $\mathrm{m} / \mathrm{z}$ 3663.326; calcd. 3662.085).

\section{3}

\section{(3) Intramolecular disulfide bond formation of the A-Chain}

The crude [Cys6,11(SH), Cys7(tBu), Cys20(Acm)] A-chain (I) $(120 \mathrm{mg}, 47.8 \mu \mathrm{mol})$ was dissolved in $20 \%$ acetonitrile in water (total $120 \mathrm{~mL}$ ). The DPDS solution $(10.51 \mathrm{mg}$ dissolved in $8 \mathrm{~mL}$ of methanol) was added to the magnetically stirred peptide solution. This reaction was complete at 30 min at RT as monitored by analytical RP-HPLC. The solution was loaded onto a preparative RP-HPLC column through the C-line for purification and freeze dried to give pure Cys6-Cys11 intramolecularly disulfide-bonded insulin A-chain, [Cys7(tBu), Cys20(Acm)] (III) (34.2 mg, $13.62 \mu \mathrm{mol}$, yield 28.5\%). MALDI-TOF MS showed a single peak for [Cys7(tBu), Cys20(Acm)] (III) at $\mathrm{m} / z 2508.88$, calcd. 2510.70.

\section{4}

\section{(4) Conversion of Cys7(tBu) to Cys7(Pyr) of A-chain}

The purified [Cys7(tBu), Cys20(Acm)] A-chain (III) $(30.0 \mathrm{mg}, 11.94 \mu \mathrm{mol})$ and 4 equivalent of DPDS (11.52 mg, $47.76 \mu \mathrm{mol})$ were dissolved in $0.78 \mathrm{~mL}$ TFA and anisole $(9: 1 \mathrm{v} / \mathrm{v})$ in an ice bath. Then, $0.78 \mathrm{~mL}$ of TFMSA/TFA $(1: 4 \mathrm{v} / \mathrm{v})$ was added to the magnetically stirred mixture, and stirring was continued for $45 \mathrm{~min}$ at $0^{\circ} \mathrm{C}$. The peptide was collected by precipitation with ice cold diethyl ether followed by centrifugation, and purified by using preparative RP-HPLC. The pure A-chain [Cys7(Pyr), 
Cys20(Acm)] (IV) (12.3 mg, $4.79 \mu \mathrm{mol}$, yield 40\%) was obtained after freeze-drying, and identified by MALDI-TOF MS ( $\mathrm{m} / \mathrm{z}$ 2564.23, calcd. 2563.85).

\section{5}

\section{(5) Combination of A-Chain with modified B-Chain}

The purified A-chain [Cys7(Pyr), Cys20(Acm)] (IV) $(10 \mathrm{mg}, 3.9 \mu \mathrm{mol})$ was dissolved in $1 \mathrm{~mL}$ of $6 \mathrm{M}$ GnHCl (0.1 M Gly/NaOH) buffer (pH 8.5). The [Cys0 (tBu), Cys7(SH), Cys19(Acm)] B-chain (II) (17 mg, $4.64 \mu \mathrm{mol})$ was dissolved in $1 \mathrm{~mL}$ of deionized water and added slowly to the magnetically stirred A-chain solution. This reaction was complete in $20 \mathrm{~min}$ at RT. The resulting peptide, [A Cys20(Acm)-B Cys19(Acm)] (V), was purified by using preparative RP-HPLC and freeze-dried to obtain $14 \mathrm{mg}(2.29 \mu \mathrm{mol}$, yield $49 \%$ calculated from the B-chain). The peptide (V) was identified by MALDI-TOF MS ( $\mathrm{m} / z$ 6113.97, calcd. 6112.94).

\section{6}

(6) Iodine oxidation to generate non-glycoinsulin (VI)

The A-B peptide [A Cys20(Acm)-B Cys19(Acm)] (V) (11 mg, $1.8 \mu \mathrm{mol})$ was dissolved in a solvent mixture of $5.6 \mathrm{~mL}$ glacial acetic acid, $0.27 \mathrm{~mL}$ of $60 \mathrm{mM} \mathrm{HCl}$. The dissolved peptide solution was then treated with iodine/acetic acid $(20 \mathrm{mM}, 7.5 \mathrm{~mL})$ to remove Acm groups. This iodine oxidation was stopped by adding ice cold diethyl ether after $45 \mathrm{~min}$ at RT. Then, the peptide was purified by preparative RP-HPLC and freeze-dried to obtain $2.1 \mathrm{mg}(0.351 \mu \mathrm{mol}$, yield $19.5 \%)$ of $\mathrm{Cys} 0(\mathrm{tBu})$ insulin analogue, non-glycoinsulin (VI). The overall yield of non-glycoinsulin (VI) calculated from the B-chain was $\sim 7 \%$. The purity of the peptide was confirmed by analytical RP-HPLC and the mass was confirmed by MALDI-TOF MS (VI, m/z 5969.34, calcd. 5970.94). 


\section{Synthesis of insulin analogue, non-glycoinsulin}

Fmoc-SPPS of insulin A chain

1)

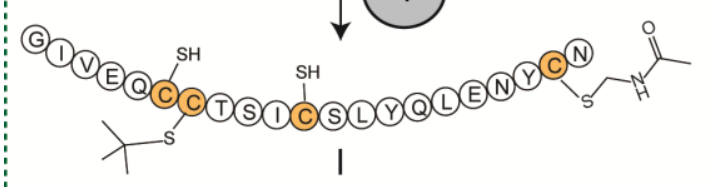

$3)$

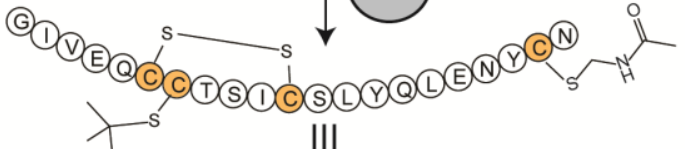

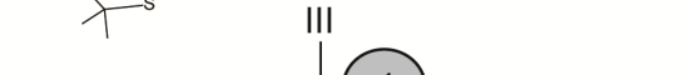

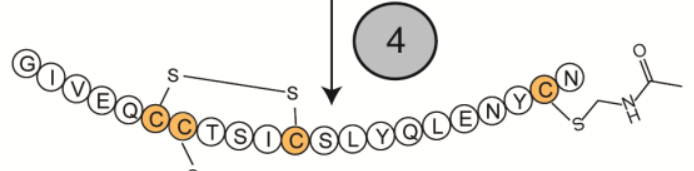

5 IV

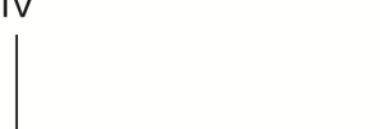

Fmoc-SPPS of insulin B chain<smiles>CC(C)(C)OCCO</smiles>

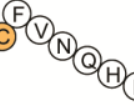

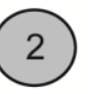<smiles>[R9][BH3-]</smiles>

(A) (D)

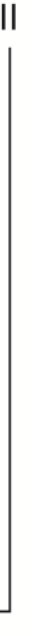

5

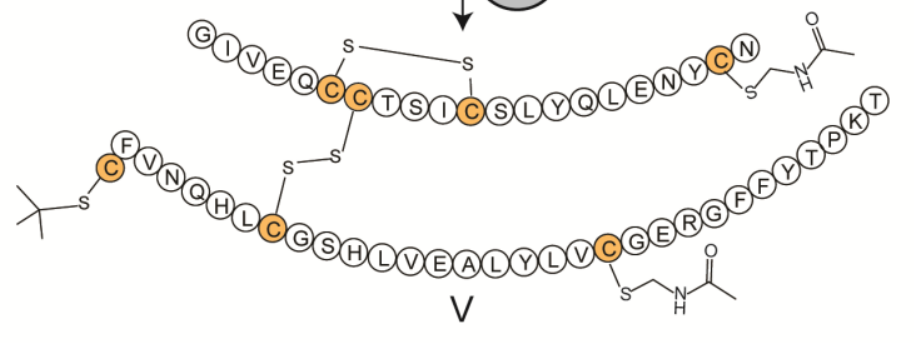

6

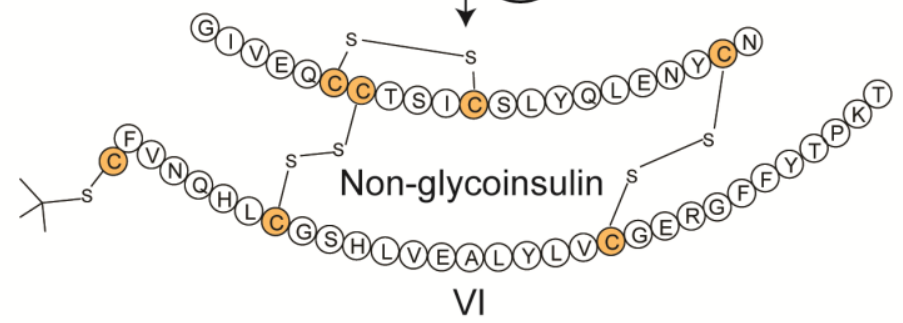


Synthesis of non-glycoinsulin: Charactersing the intermdetiates with RP-HPLC

Analytical HPLC system Waters ${ }^{\text {TM }} 600$ coupled with a Waters ${ }^{T M} 2487$ detector (Phenomenex Gemini $5 \mu \mathrm{m} \mathrm{C18} 11 \mathrm{~A}^{\mathrm{O}}$ )

Fmoc-SPPS of insulin A chain
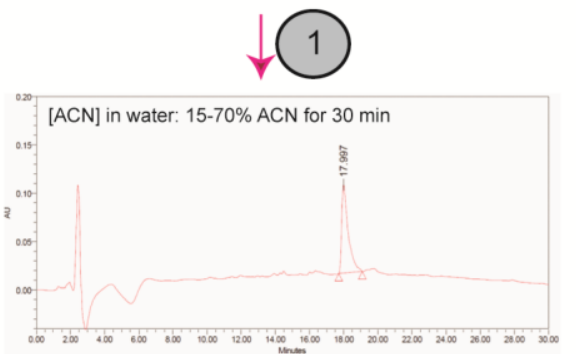

1
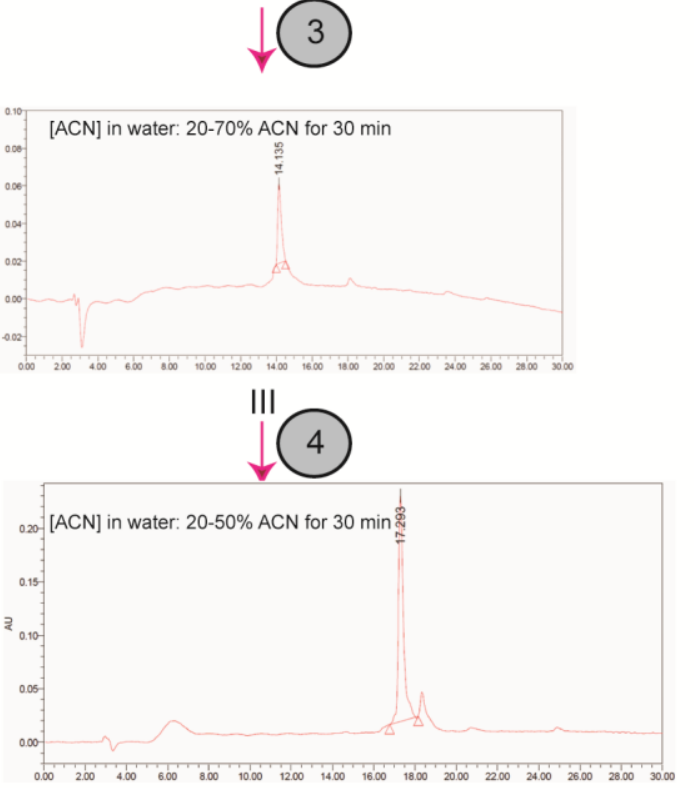

IV

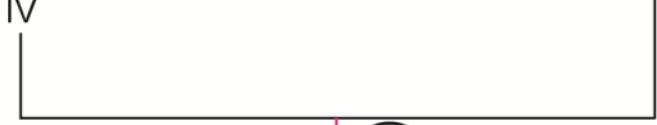

5

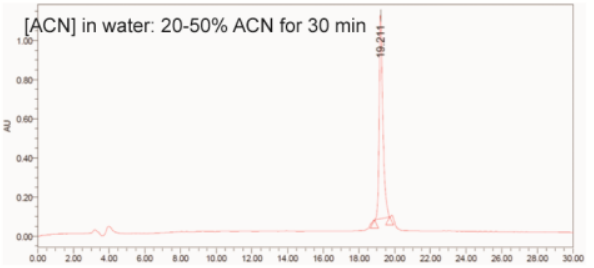

6

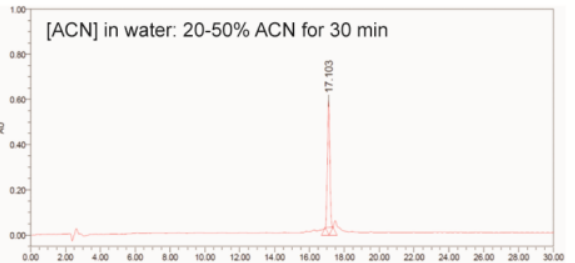

VI 
Synthesis of non-glycoinsulin: Charactersing the rection intermdetiates with MALDI MS

Fmoc-SPPS of insulin A chain

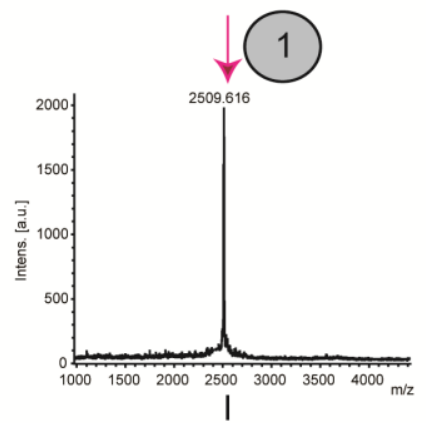

$3)$
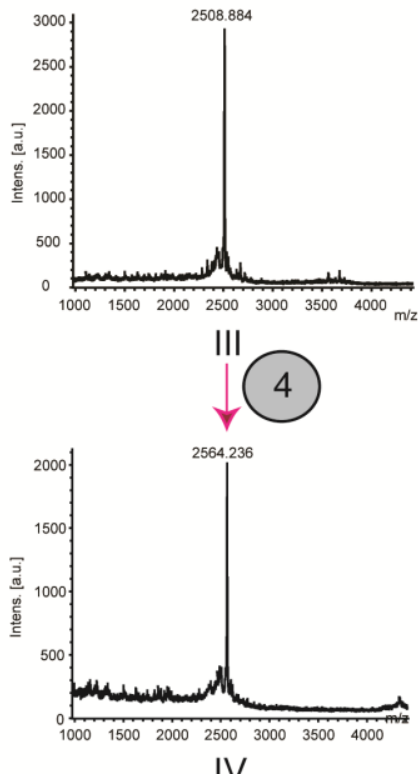

Fmoc-SPPS of insulin B chain

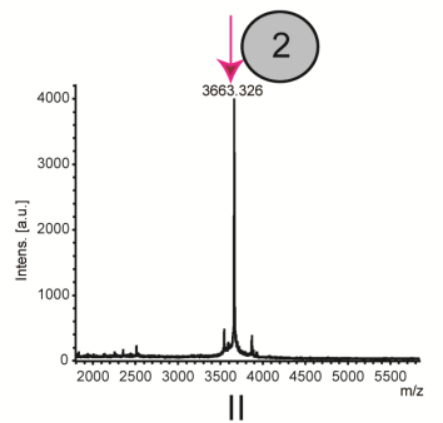

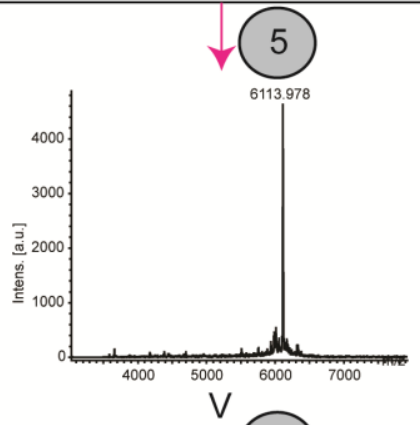

6

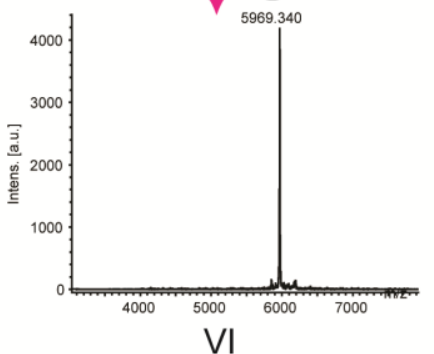




\section{Glycosylation by chemical means \\ (Figure 1 - Main Text; Figures S4)}

\section{7}

(7) Thiol insulin, a starting material for glycosylation

The purified Cys0(tBu) insulin analogue (non-glycoinsulin; VI) $(1.8 \mathrm{mg}, 0.3 \mu \mathrm{mol})$, was dissolved in $0.2 \mathrm{~mL}$ TFA and anisole $(9: 1 \mathrm{v} / \mathrm{v})$ in an ice bath. Then, $0.2 \mathrm{~mL}$ of TFMSA/TFA $(1: 4 \mathrm{v} / \mathrm{v})$ was added to peptide solution $\left(30 \mathrm{~min}\right.$ at $\left.0^{\circ} \mathrm{C}\right)$. Ice cold ether was added after $30 \mathrm{~min}$ to precipitate the peptides. The resulting thiol insulin (VII) was purified by preparative RP-HPLC. This reaction needs extra care and balance between time, concentration and temperature. We were able to reduce reaction time to $3 \mathrm{~min}$ instead of $30 \mathrm{~min}$ when we carried out a small scale reaction $(0.4 \mathrm{mg}$ in $5 \mu \mathrm{L}$ TFA/anisole (9:1) and 5 $\mu \mathrm{L}$ TFMSA/TFA (1:4). For this small scale highly concentrated reaction, 3 minutes was enough to obtain the desired product with similar yield. A longer reaction time may cause reshuffling of the disulfide bonds in peptides. Therefore, we need to always monitor the reaction so that we avoid side reactions. The purity of thiol insulin (VII) was confirmed by analytical RP-HPLC and the mass was confirmed by MALDI-TOF MS ( $\mathrm{m} / \mathrm{z}$ 5910.06, calcd. 5914.94, Figure 1F; Figure S3). The yield of this reaction was found to be $\sim 68 \%(1.2 \mathrm{mg}$ of VII; $0.203 \mu \mathrm{mol})$.

\section{8}

\section{(8) Extraction of sugars from egg yolks and conversion to Br-derivative}

The human type complex disialo-oligosaccharide was isolated from egg yolks ${ }^{1}$ and derivatized to form bromo-acetamidyl undecasaccharide (VIII, Figure S3) as prevously reported ${ }^{2}$.

(9) Glycosylation of insulin - Reaction optimization 
To optimise this reaction, the reactions were undertaken in a range of $\mathrm{pH}(\mathrm{pH}$ 5.5-7.5 in $25 \mathrm{mM}$ or 100 $\mathrm{mM}$ phosphate buffer or Tris buffer) with 2-10 equivalent of sugar. The peptide was found to be slightly insoluble or to gradually become insoluble (turbid) in these buffers. The major product observed in all these conditions was insulin dimer (X, Figure S3). Finally, this reaction was carried out in Milli-Q water (pH 5-6) in which both the peptide and sugars were soluble. The non-glycoinsulin peptide (VII) (1 mg, $0.17 \mu \mathrm{mol})$ was dissolved in $1.5 \mathrm{~mL}$ of Milli-Q water. Separately, 3 equivalent of Br-disialooligosaccharide (VIII, overnight dried) was dissolved (1.2 mg; $0.5 \mu \mathrm{mol})$ in $0.5 \mathrm{~mL}$ of Milli-Q water. Then peptide was added to this sugar solution in a dropwise manner (total volume of $2 \mathrm{~mL}$ ). The reaction was very slow but the major peak was found to be the desired product, glycoinsulin (IX; Figure 1; Figure S3) with a minor product being the dimer of insulin (X, Figure 1). The peptide was purified after 24 hrs with one single injection into prep HPLC. The reaction can be accelerated by adding 6-9 equivalent sugars and increasing temperature (e.g. $37^{\circ} \mathrm{C}$ ). Despite having a free thiol, thiol insulin does not scramble $\left(1 \mu \mathrm{g} / \mu \mathrm{l}\right.$; tested between -4 to $\left.25^{\circ} \mathrm{C}\right)$. However, it has tendency to form dimer at high concentration and we observed quantitive dimer formation if thiol insulin (at $1 \mu \mathrm{g} / \mu \mathrm{L}$ water) is left at RT without Br-glycans for $24 \mathrm{~h}$. The purity of glycoprotein was confirmed by analytical RPHPLC (Figure 1E) and the mass was confirmed by MALDI-TOF MS ( $\mathrm{m} / \mathrm{z} 8177.13$, calcd. 8178.89, Figure $1 \mathrm{G})$. The yield of the glycosylation reaction was found to be $57.64 \%(\sim 60 \%)(0.8 \mathrm{mg}$ of IX; $0.098 \mu \mathrm{mol})$. 


\section{Figure S4}

\section{Glycosylation by chemical means}
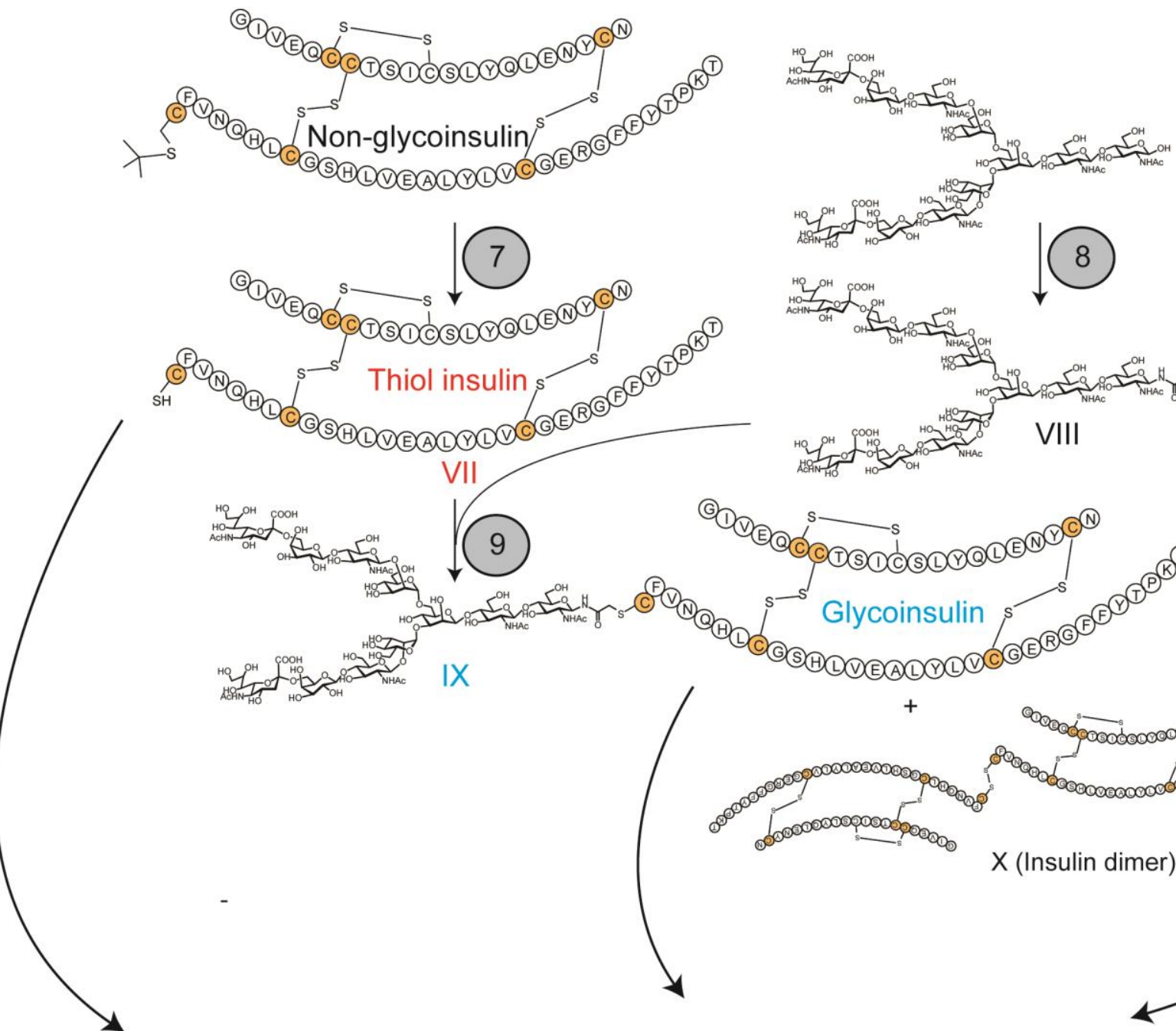

$3 \sec ^{2}$
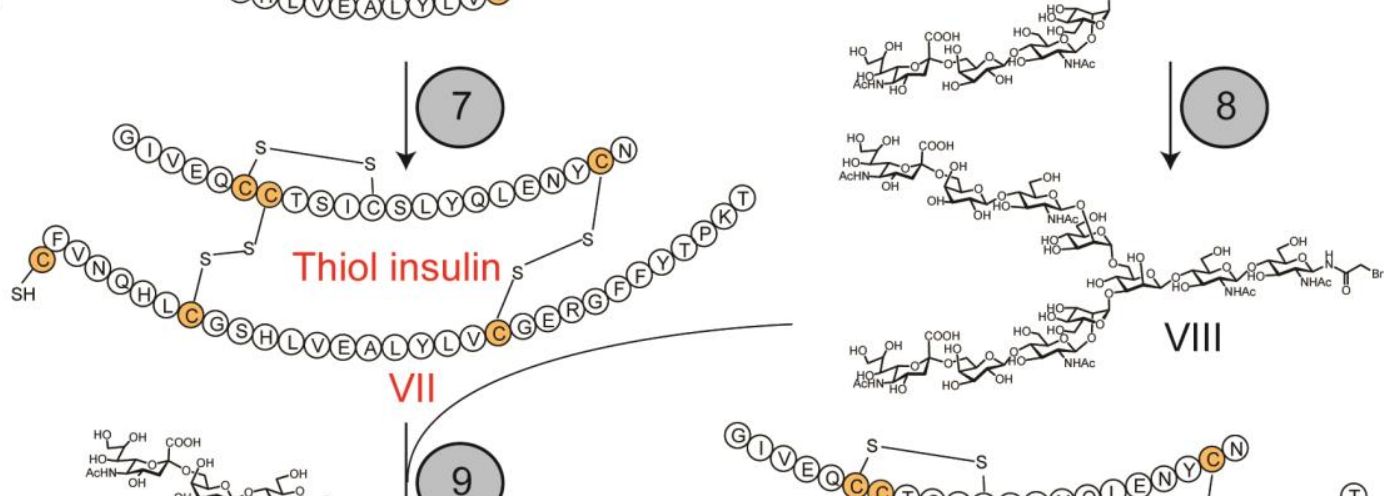

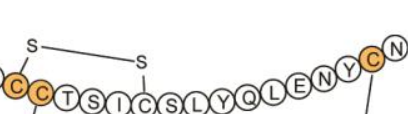
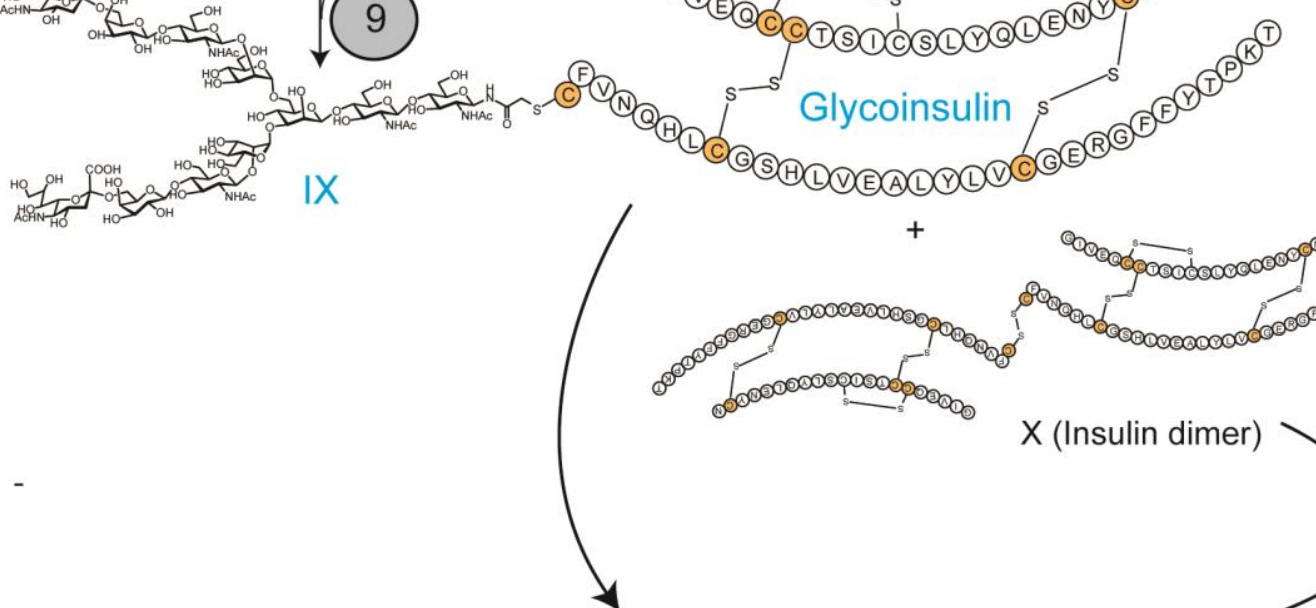

VII

IX Analytical HPLC Waters ${ }^{\mathrm{TM}} 600$ coupled with a waters ${ }^{\mathrm{TM}} 2487$ detector. $[\mathrm{ACN}]$ in water $=20-50 \%$ for $30 \mathrm{~min}$
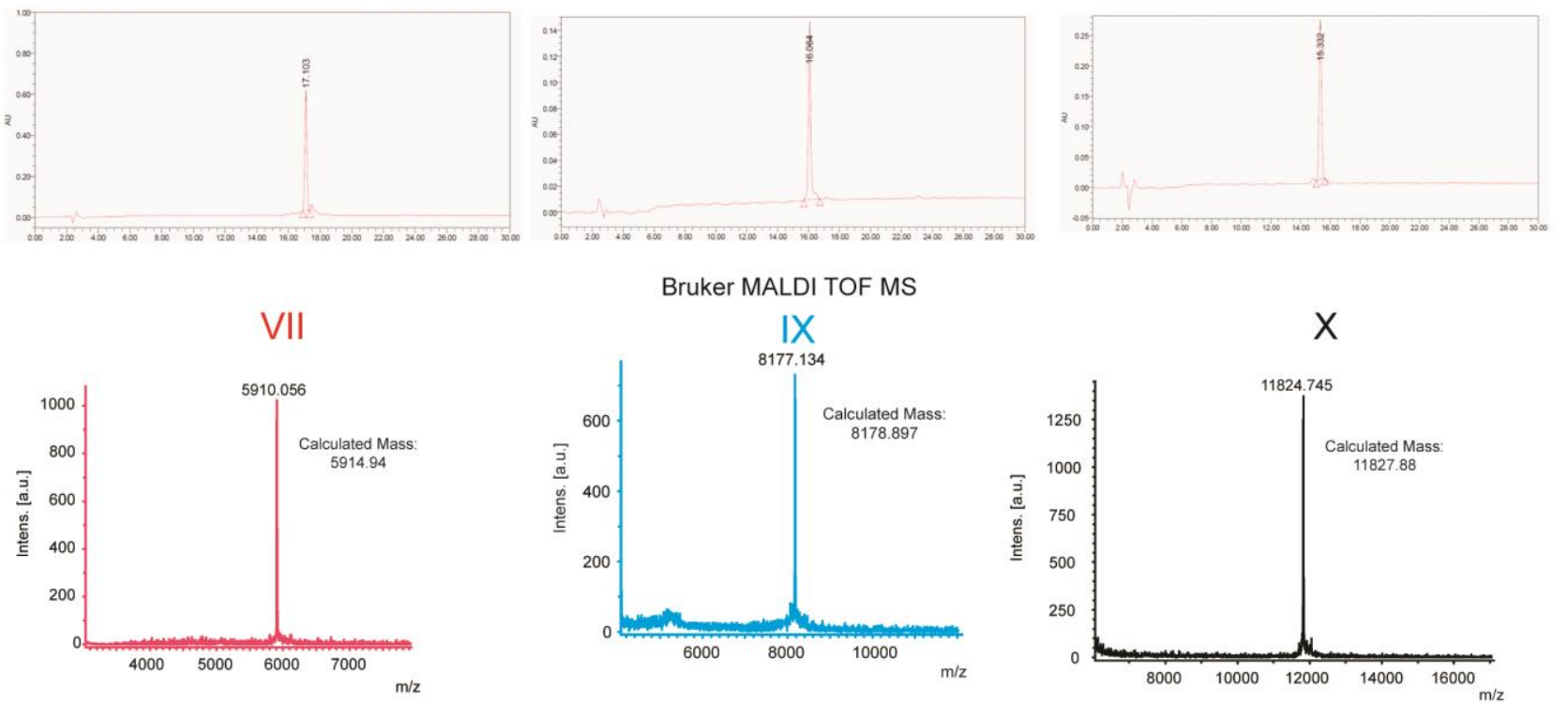


\section{Quantification of peptide content IR Direct Detect and HPLC}

The actual peptide content was determined using Direct Detect assay-free sample cards and the Direct

Detect spectrometer (MerckMillipore). Each card contains hydrophilic spots surrounded by a hydrophobic ring to retain the analyzed sample within the infrared beam for convenient sample application and analysis. All measurements were performed using $2 \mu \mathrm{L}$ of sample solution. The glycoinsulin was found to have a $20 \%$ peptide content. We then injected same concentration of glycoinsulin and native insulin into HPLC to confirm the same peak area under the curve and adjusted to $100 \%$ peptide content for both peptides. Then the adjusted net peptide content was used to prepare the samples for the following assays: insulin receptor binding assay, insulin tolerance test, atomic force microscopy fibrillation assay, circular dischroism spectroscopy and serum stability studies.

\section{Insulin receptor binding assay}

\section{(Figure 2 - Main Text)}

Receptor binding was measured as described by Denley ${ }^{3}$. Briefly, IGF-1R-negative cells overexpressing the insulin receptor B (IR-B) were generated. Cells were serum-starved for $4 \mathrm{~h}$ before lysis. Lysates were captured in a 96 well plate previously coated with anti-IR antibody. Approximately 500,000 fluorescent counts of europium-labelled insulin were added to each well along with increasing concentrations of unlabelled competitor and incubated for $16 \mathrm{~h}$ at $4^{\circ} \mathrm{C}$. After washing time-resolved fluorescence was measured using $340 \mathrm{~nm}$ excitation and $612 \mathrm{~nm}$ emission filters with a BMG Lab technologies Polarstar fluorometer (Mornington, Australia). Insulin and synthetic analogues curves are from four separate experiments with each point performed in triplicate.

\section{Insulin tolerance tests}

\section{(Figure 3 - Main Text)}

Insulin tolerance tests were performed as previously described ${ }^{4}$. Briefly, fed $8-10$-week-old male C57BL/6J mice were anesthetized with sodium pentobarbitone $\left(100 \mathrm{mg} \cdot \mathrm{kg}^{-1}\right)$ and injected 
intraperitoneally (i.p.) or subcutaneously (s.c.) with 0.75 unit of insulin (actrapid), non-glycoinsulin, glycoinsulin or glargine per kg body weight. Blood samples were taken from the tail vein, and glucose concentration was measured using a glucometer (Precision Q.I.D., MediSense, MA, USA).

\section{Atomic force microscopy studies for fibrillation}

\section{(Figure 4 - Main Text)}

For atomic force microscopy experiments, $200 \mu \mathrm{M}$ and $50 \mu \mathrm{M}$ insulin solutions were prepared by dissolving human insulin powder in a buffer solution $(50 \mathrm{mM} \mathrm{KCl} / \mathrm{HCl}$ in Milli-Q water, $\mathrm{pH}$ 1.6). Insulin solutions were incubated in polypropylene microcentrifuge tubes at $60{ }^{\circ} \mathrm{C}$ for a maximum of $24 \mathrm{~h}$. After desired time intervals $10 \mu \mathrm{L}$ of insulin solution was transferred to a polypropylene microcentrifuge tube and diluted to different concentrations with $50 \mathrm{mM} \mathrm{KCl} / \mathrm{HCl}$ buffer solution and quenched to $0{ }^{\circ} \mathrm{C}$ to rapidly inhibit further aggregation. Then $5 \mu \mathrm{L}$ diluted insulin solution was placed on a freshly cleaved mica substrate. Insulin aggregates were allowed to adsorb on mica for 5mins. The excess insulin aggregates were washed dropwise with Milli-Q water for 2-3 times and then dried with gentle flow of nitrogen. Topographic images of insulin aggregates were collected with an Dimension iCon Atomic Force Microscopy (Bruker, Billerica, MA, USA). Tapping mode AFM images were recorded using silicon cantilevers (model RTESPA, Veeco, Santa Barbara, CA) with resonance frequency $\sim 300 \mathrm{kHz}$, nominal tip radius $8 \mathrm{~nm}$ and nominal spring constant $42 \mathrm{~N} / \mathrm{m}$.

\section{Circular dichroism studies}

\section{(Figure 5A - Main Text)}

CD spectra data of insulin and glycoinsulin were recorded using a Aviv Model 410 (Piscataway, NJ) spectrophotometer at $25{ }^{\circ} \mathrm{C}$ using $1 \mathrm{~mm}$ path length cell. The peptides were dissolved in $10 \mathrm{mM}$ phosphate buffer at $\mathrm{pH} 7.5$. The parameters used to obtain the spectra were wavelengths 190 to $250 \mathrm{~nm}$ with a data pitch of $0.1 \mathrm{~nm}$, continuous scanning mode at a speed of $50 \mathrm{~nm}$ per minute and the number of 
accumulations taken per peptide was 3 . The concentration of peptide used was $0.1 \mu \mathrm{g} / \mu \mathrm{L}$ for insulin and $0.17 \mu \mathrm{g} / \mu \mathrm{L}$ for glycoinsulin. We converted this concentration to molar concentration when calculated mean residue weight ellipticity for comparing the $\mathrm{CD}$ data and calculating helicity as described in the main text.

\section{Serum stability studies}

\section{(Figure 5B - Main Text)}

Proteolytic stability of glycoinsulin and native human insulin was assessed by incubating the peptides $(0.02 \mathrm{ug} / \mu \mathrm{l})$ in a solution of $99.6 \%$ human serum in $\mathrm{PBS}(\mathrm{pH} 7.4)$ at $37^{\circ} \mathrm{C} 45 \mathrm{uL}$ of each samples were removed at various time points $(1 \mathrm{~h}, 8 \mathrm{~h}, 24 \mathrm{~h}, 48 \mathrm{~h}$ and $72 \mathrm{~h})$, and $90 \mathrm{uL}$ of acetonitrile was added to precipitate plasma proteins, which were removed by centrifugation $(6200 \mathrm{rpm}, 3 \mathrm{mins})$. The amount of intact peptides remaining in the supernatant of each sample was determined by RP-HPLC, by measuring the area under the peak at appropriate retention time compared to the peak area of glycol hINSL at time zero $(100 \%)$. Both the glycoinsulin and native human insulins were assayed in duplicate $(\mathrm{n}=2)$.

\section{References}

1. Kajihara, Y.; Suzuki, Y.; Yamamoto, N.; Sasaki, K.; Sakakibara, T.; Juneja, L. R., Prompt chemoenzymatic synthesis of diverse complex-type oligosaccharides and its application to the solid-phase synthesis of a glycopeptide with Asn-linked sialyl-undeca- and asialo-nonasaccharides. Chemistry 2004, $10(4), 971-85$.

2. Murase, T.; Tsuji, T.; Kajihara, Y., Efficient and systematic synthesis of a small glycoconjugate library having human complex type oligosaccharides. Carbohydr Res 2009, 344 (6), 762-70.

3. Denley, A.; Bonython, E. R.; Booker, G. W.; Cosgrove, L. J.; Forbes, B. E.; Ward, C. W.; Wallace, J. C., Structural determinants for high-affinity binding of insulin-like growth factor II to insulin receptor (IR)-A, the exon 11 minus isoform of the IR. Mol Endocrinol 2004, 18 (10), 2502-12. 
4. Wong, N.; Fam, B. C.; Cempako, G. R.; Steinberg, G. R.; Walder, K.; Kay, T. W.; Proietto, J.; Andrikopoulos, S., Deficiency in interferon-gamma results in reduced body weight and better glucose tolerance in mice. Endocrinology 2011, 152 (10), 3690-9. 